\title{
Influence of carbon nanofiber clustering on the chemo-mechanical behavior of cement pastes
}

Lesa Brown and Florence Sanchez ${ }^{*}$

Department of Civil and Environmental Engineering, Vanderbilt University, VU Station B \#351831, Nashville, Tennessee, USA

\begin{abstract}
The influence of carbon nanofiber (CNF) clustering on the chemo-mechanical behavior of cement pastes subjected to a decalcifying environment was studied. Portland cement pastes with and without CNFs were exposed to a concentrated solution of ammonium nitrate to accelerate decalcification. Microstructural changes and evolution of the porosity were examined as a function of exposure duration. Changes in the flexural response of the cement paste with CNFs were studied and reviewed in relation to CNF clustering and microstructural evolution. Results showed a strong coupling between decalcification, CNF clustering, microstructural evolution, and the flexural properties of the cement paste. After 7 days of decalcification by $\mathrm{NH}_{4} \mathrm{NO}_{3}$, the $\mathrm{CNF}$ clusters acted as weak zones that reduced the flexural strength retention of the cement paste. However, after 125 days of decalcification by $\mathrm{NH}_{4} \mathrm{NO}_{3}$, a dissolution-filling mechanism within the clusters created a better bond with the surrounding cement paste, slowing down the loss of flexural strength and providing added ductility to the cement paste.
\end{abstract}

Keywords: Carbon nanofibers; Durability; Decalcification; Cement-based materials; Agglomeration

\subsection{Introduction}

Carbon nanotubes/nanofibers (CNTs/CNFs) possess a number of unique properties, including exceptional mechanical properties and high aspect ratios, that make them attractive for reinforcement of cement-based materials at the nano-level [1-3]. The contribution of CNTs/CNFs to the reinforcement is strongly dependent upon their distribution and arrangement in the cement matrix - CNT/CNF clustering has proven to

*Corresponding author. Tel.: 615-322-5135. Email Address: florence.sanchez@vanderbilt.edu (F. Sanchez). 
be a critical factor in influencing the material mechanical and electrical properties [4]. Despite much effort to homogeneously disperse CNTs/CNFs in the cement matrix [5-7], there is still evidence of the presence of localized sub-micro and micro-scale clusters and inhomogeneous distribution of CNTs/CNFs [5, 7-12]. While the occurrence of CNT/CNF clustering may constitute a defect causing a loss of mechanical properties, it may not always be undesirable. For example, it has been shown for polymer composites to enhance certain mechanical properties [13] and to favor the formation of a percolating network for electrical conductivity [14-16]. During their service life, cement-based materials are subjected to a wide variety of weathering induced degradation. Given that perfect dispersion at the individual fiber level may not be achievable and that controlled clustering may even be desirable for certain applications, it is therefore critical to understand the effect of CNT/CNF clustering on the durability of cement-based materials exposed to aggressive environments.

Decalcification is closely associated with various types of concrete degradation [17], including during sulfate attack and leaching by exposure to neutral or acidic waters. It is a complex dissolution-diffusion process that involves the removal of calcium from the cement paste and results in both chemical and physical degradation. A loss of cohesion of the cement paste, an increase in porosity, and a decrease in the mechanical properties are all common manifestations of decalcification $[17,18]$. While the addition of CNFs is anticipated to improve the cement paste durability through pore refinement $[19,20]$ and by increasing the cohesion of the paste, the influence of a non-uniform dispersion of the CNFs, specifically CNF clustering on the cement paste during exposure to a decalcifying environment, is unclear. Yet, CNF clustering is expected to introduce a secondary porosity into the cement paste, which could significantly impact the chemical and mechanical property evolution during decalcification. This paper focuses on CNFs in Portland cement paste and reports on the effects of CNF clustering on the chemomechanical behavior of cement pastes subjected to a decalcifying environment. Portland cement pastes with and without CNFs were exposed to a concentrated solution of ammonium nitrate to accelerate decalcification. Microstructural changes and evolution of the porosity were examined as a function of exposure duration. Changes in the flexural 
response of the pastes with CNFs were studied and reviewed in relation to CNF clustering and microstructural evolution.

\subsection{Materials and methods}

\subsection{Cement paste preparation}

Commercially available, vapor grown, Pyrograf ${ }^{\circledR}$-III PR-19-LHT CNFs (Applied Sciences, Inc., Cedarville, Ohio) were used as received from the manufacturer. Type I/II Portland cement (Lafarge, Nashville, Tennessee) was used as the cementitious material, and a polycarboxylate-based high range water reducer (HRWR), Glenium 7500 (BASF, Ludwigshafen, Germany), was used to promote the dispersion of the CNFs in the cement paste $[5,7,21]$. Two types of paste were prepared: a plain Portland cement paste (reference cement paste) and a Portland cement paste containing 0.2\% CNFs per mass of cement (cement paste with CNFs). The HRWR was used at a loading of $1 \%$ per mass of cement, and a water to cement ratio of 0.28 was used for all mixes. The same amount of HRWR was used for both the reference cement paste and the cement paste with CNFs so that any differences seen between the two cement pastes during decalcification could be attributed solely to the addition of the CNFs. The water, HRWR, and CNFs (where applicable) were combined and sonicated with a bath sonicator (Aquasonic model 250D) for 30 minutes before mixing with the cement powder. After mixing, the pastes were poured into $2.54 \mathrm{~cm} \times 2.54 \mathrm{~cm} \times 69 \mathrm{~cm}$ (height $\mathrm{x}$ width $\mathrm{x}$ length) beam molds and compacted by hand. The beams were allowed to cure at room temperature under $100 \%$ relative humidity for a minimum of 28 days and sectioned into shorter beams with a length of $11.5 \mathrm{~cm}$ prior to decalcification.

\subsection{Accelerated decalcification}

After curing, some cement pastes were exposed to a concentrated solution of ammonium nitrate $\left(\mathrm{NH}_{4} \mathrm{NO}_{3}\right)$. $\mathrm{NH}_{4} \mathrm{NO}_{3}$ accelerates decalcification by increasing the solubility of calcium [17]. Decalcification of cement paste by $\mathrm{NH}_{4} \mathrm{NO}_{3}$ has been shown to be similar to decalcification by water $[17,18,22,23]$ : both yield preferential dissolution of calcium 
hydroxide $(\mathrm{CH})$ followed by progressive decalcification of the calcium-silicate-hydrate (C-S-H) phases [22]. Each specimen was immersed in an enclosed plastic container containing $1 \mathrm{~L}$ of $\mathrm{NH}_{4} \mathrm{NO}_{3}$ solution at a concentration of $480 \mathrm{~g} / \mathrm{L}(6 \mathrm{M})$ for $7,14,28$, and 125 days. Five specimens of each cement paste (with and without CNFs) were immersed for each exposure period. The $\mathrm{pH}$ of the solution was periodically monitored to ensure that no renewal of the solution was needed. At the end of each exposure period, the specimens were stored in Milli-Q water until further testing.

\subsection{Characterization}

\subsubsection{CNF cluster and interphase region analysis}

The 3D internal physical structure of the cement paste with CNFs was examined using $\mathrm{x}$ ray micro-computed tomography (micro-CT). The micro-CT projection images were acquired using a Scanco Medical $\mu$ CT50. Each sample was scanned using a voxel size of $20 \mu \mathrm{m}$ with $\mathrm{x}$-ray source settings of $90 \mathrm{kVp}$ and $200 \mu \mathrm{A}, 1000$ projections per $360^{\circ}$, and an integration time of $1000 \mu \mathrm{s}$. The Scanco $\mu$ CT Evaluation Program V6.5-1 and the $\mu \mathrm{CT}$ Ray V4.0-1 3D software were utilized for 2D and 3D image reconstructions. The air voids and CNF clusters were segmented from the cement paste using a threshold of 250 per thousand, a Gaussian noise filter of 1.2, and a Gauss support of 3. SEM analysis was used to confirm the presence of air voids and CNF clusters seen in the micro-CT images. In addition, the 2D spatial and size distributions of the CNF clusters were characterized using the image mapping system of a New Wave UP-213 Laser Ablation System. A total of 1350 images ( 27.6 x 20.6 pixels each) were collected and assembled into a single image, which represented the entire cross-section of the paste. The CNF clusters were then analyzed by subjecting the image to thresholding techniques and particle analysis using ImageJ, a Java-based open source digital image processing software (National Institute of Health, Bethesda, Maryland, USA). Due to resolution limitations with the image mapping system, only CNF clusters larger than $0.007 \mathrm{~mm}^{2}$ were included in the analysis.

Microstructural analysis of the CNF clusters and interphase regions before and after decalcification by $\mathrm{NH}_{4} \mathrm{NO}_{3}$ was conducted using an environmental FEI Quanta FEG 650 
high resolution scanning electron microscope (ESEM) equipped with a Schottky field emission gun, digital imaging, and an energy dispersive X-ray spectrometer (EDS). Fracture surfaces and polished surfaces were mounted on an aluminum stage using double-sided carbon tape. Samples were polished using a series of polishing cloths of increasingly finer grit $(240,400,600,1200$, and 2500). An accelerating voltage of $20 \mathrm{kV}$, a working distance of $10.5 \mathrm{~mm}$, and a spot size of 3.5 were used for digital imaging and EDS studies. Copper was used as a quantifying element for EDS semi-quantitative work. A pressure of $130 \mathrm{~Pa}$ was maintained when working in ESEM mode.

\subsubsection{Elemental depth profile analysis}

Elemental depth profiles of the cement pastes before and after decalcification were obtained by profile grinding and $\mathrm{x}$-ray fluorescence (XRF) measurement of the powder samples using a Thermoscientific Niton XL3 Portable XRF Analyzer. Each exposed paste cross-section was segmented at $2.5 \mathrm{~mm}$ increments to obtain XRF samples that corresponded to a depth profile. Each sample was then pulverized into a fine powder and manually compacted into a sample cup for XRF measurements. Relative intensity values obtained from micro-CT projection images were used to calibrate the XRF measurements to account for changes in cross-section density occurring in the cement pastes as a result

of decalcification. The relative intensity values of the non-decalcified pastes were used to create a unitless calibration factor (i.e., a ratio of the decalcified paste intensity value at a given location to that of the non-decalcified paste intensity value).

\subsubsection{D porosity mapping and distribution}

A SEM counting technique modified from [24] was utilized to determine the 2D porosity (areal porosity) distribution of the cement pastes as a function of exposure duration. SEM porosity mapping allows for the examination of porosity changes as a function of location and therefore can capture the degradation-induced porosity gradient occurring during decalcification. The technique involved collecting backscattered electron images from the polished surface of a cement paste cross-section in a grid-like fashion (a minimum of 200 images was collected from each cement paste cross-section). Each 
image was then processed using MATLAB to yield a gray-scale histogram. The areal porosity of each image was calculated by fitting the primary peak of the histogram with a Gaussian curve. The inflection point in the ascending region of the Gaussian curve was calculated, and the tangent line was computed for that point by taking the analytical first derivative of the Gaussian curve. The threshold value for the areal porosity was then defined as the intersection of the tangent and the abscissa. Once an areal porosity value was calculated for each image, a 3D surface contour plot of the cross-section areal porosity was created utilizing built-in functions in MATLAB. The median areal porosity of the various zones of degradation found throughout the cross-section was then determined. The areal porosity determined by the SEM image method only accounts for part of the total porosity given the limitations of the SEM image resolution and the grid collecting technique and should only be used to compare datasets that were analyzed using the same method.

\subsubsection{Mechanical testing}

Flexural testing of the cement pastes before and after decalcification was performed using a Tinius Olsen Super L 60K $(300 \mathrm{kN})$ universal testing machine. A 3-point bending test set-up with a loading rate of $0.1 \mathrm{~mm} / \mathrm{min}$ was utilized. A minimum of five specimens of each cement paste was used. All specimens were tested in a saturated-surface-dried condition.

\subsection{Results and discussion}

\subsection{CNF dispersion state and cluster characteristics}

Despite a uniform dispersion of the CNFs in solution before mixing, a large number of clusters of varied size and shape were found throughout the cement paste (Fig. 1). Statistical analysis of the clusters in a 2D cross-section indicated that the cluster size ranged from $125 \mu \mathrm{m}$ up to $1500 \mu \mathrm{m}$ (max Feret diameter). Greater areal coverage $(13.0 \%)$ and larger size clusters (Fig. 2a) were seen in the first $2 \mathrm{~mm}$ from the top edge (as poured) of the paste compared to the interior ( $1.3 \%$ areal coverage), indicating migration of the 
CNFs with the bleed water during curing. Overall, a uniform spatial distribution of the clusters was observed throughout the interior of the cement paste (Fig. 2b).

The CNF clusters were an entangled mass of fibers with large plates of $\mathrm{CH}$ scattered throughout the cluster (Fig. 3a). The presence of $\mathrm{CH}$ plates was consistent with the Le Chatelier hydration process (i.e., solution-crystallization step) [25] and a greater mobility of calcium ions compared to silicon ions $\left(1.6 \times 10^{-5} \mathrm{~cm}^{2} \mathrm{~s}^{-1}\right.$ [26] vs. $0.9 \times 10^{-5} \mathrm{~cm}^{2} \mathrm{~s}^{-1}$ [27], respectively), leading to the formation of $\mathrm{CH}$ crystals. No other $\mathrm{CH}$ plates of this size were found in the surrounding cement paste or the reference paste, indicating an influence of the CNF clusters on the morphology and spatial distribution of certain hydration products. The presence of sulfur inside the clusters was also detected and was attributed to a surface residual from the CNF manufacturing process.

Each CNF cluster was surrounded by an interphase region of $c a .20-30 \mu \mathrm{m}$ thick (Fig. 4) that had a higher porosity and a different chemical composition than the surrounding cement paste. The thickness of the interphase regions was similar for all clusters and was thought to be dependent on the size of the cement grains rather than the size of the clusters. The interphase regions had a greater median areal porosity (5.5\%) compared to the rest of the cement paste (4.1\%). These regions also had a lower calcium content, a more uniform silicon content, and a higher potassium content, and were characterized by the absence of unhydrated cement particles (Fig. 5). Similar observations have been reported for the interfacial transition zone between aggregate and cement paste in concrete $[28,29]$.

\subsection{Effect of decalcification on CNF clusters and paste microstructure}

Visible manifestation of decalcification was characterized by the presence of a dark core surrounded by a series of layers (Fig. 6). The size of the core and number of layers changed with exposure duration, as a result of the complex chemical phenomena associated with the decalcification process. After 7 days of decalcification by $\mathrm{NH}_{4} \mathrm{NO}_{3}$, two zones could clearly be seen in the cross-section of both cement pastes: a dark, interior core and a lighter-colored outer layer. The size and shape of the interior core were similar for both pastes. After 28 days of decalcification by $\mathrm{NH}_{4} \mathrm{NO}_{3}$, the two zones remained, although the interior core was smaller for both pastes. After 125 days of 
decalcification by $\mathrm{NH}_{4} \mathrm{NO}_{3}$, three visible zones could then be observed: a light-colored outer layer, a slightly darker middle layer, and a dark interior core. The paste with CNFs maintained a square-shaped core, while the reference paste showed a more rounded interior core, indicating that decalcification of the paste with CNFs had occurred to a lesser depth than the reference paste. This was confirmed by the calcium profile of the paste with CNFs that exhibited higher calcium in the middle layer and interior core compared to the reference cement paste (Fig. 7). Exposure to $\mathrm{NH}_{4} \mathrm{NO}_{3}$ had little effect on the silicon profile for both pastes.

CNF clusters. After 7 days of decalcification by $\mathrm{NH}_{4} \mathrm{NO}_{3}$, the CNF clusters in the outer layer of the paste showed dissolution of the $\mathrm{CH}$ plates (Fig. 8) with a preferential leaching of the calcium into the surrounding cement paste and an increased presence of silicon throughout the cluster, indicating a transition from a $\mathrm{CH}$ rich environment toward a low calcium C-S-H environment. The preferential leaching of calcium from the clusters led to the opening of the inter-fiber voids, creating weak zones within the paste. In contrast, the clusters located in the interior core of the paste remained high in calcium, though all the $\mathrm{CH}$ plates had dissolved. After 125 days of decalcification by $\mathrm{NH}_{4} \mathrm{NO}_{3}$, the CNF clusters in the outer layer had lost most of the calcium and silicon content with only the presence of the entangled CNFs remaining (Fig. 9). The clusters in the middle layer and interior core showed, however, uniform formation of C-S-H throughout the cluster, filling the inter-fiber voids. The $\mathrm{C}-\mathrm{S}-\mathrm{H}$ found in the middle layer clusters had a higher calcium C-S-H than the surrounding cement paste (Fig. 3b) while that found in the interior core clusters had a similar calcium level to the surrounding cement paste.

Interphase regions. After 7 days of decalcification by $\mathrm{NH}_{4} \mathrm{NO}_{3}$, the interphase regions of the clusters located in the outer layer could no longer be seen while that of the clusters in the interior core were still clearly distinguishable and mainly defined by the presence of silicon and potassium (Fig. 8). After 125 days of decalcification by $\mathrm{NH}_{4} \mathrm{NO}_{3}$, the interphase regions could only be seen for the clusters located in the middle layer and interior core and were only defined by the presence of silicon (Fig. 9). The calcium seen in the interphase regions after both 7 and 125 days of decalcification by $\mathrm{NH}_{4} \mathrm{NO}_{3}$ had a similar intensity to that of the surrounding cement paste and could no longer be used as a signature of the interphase regions. 


\subsection{Porosity distribution and evolution during decalcification}

The presence of the CNF clusters clearly influenced the distribution of the initial areal porosity over the cement paste cross-section and its evolution during decalcification (Fig. 10). Prior to decalcification, both cement pastes had a similar overall median areal porosity (4.1\%). However, zones of higher areal porosity, ranging from $c a$. 10 to $20 \%$, could be seen throughout the cross-section of the paste with CNFs (Fig. 10), most likely as a result of the presence of the CNF clusters. The CNFs in the clusters formed a highly entwined, meshed structure, resulting in an inter-fiber pore network and thus, an increase in local porosity. These results further suggested that the presence of CNFs led to a pore refinement of the surrounding cement paste as shown from the observation of a similar overall median areal porosity compared to the reference cement paste despite the presence of zones of higher areal porosity.

After 7 days of decalcification by $\mathrm{NH}_{4} \mathrm{NO}_{3}$, two clearly defined zones of areal porosity could be identified for both cement pastes (Fig. 10). The outer layer of the pastes exhibited a more drastic increase in areal porosity ( $c a .60 \%$ for both pastes) than the interior core ( $\mathrm{ca} .5 \%$ for both pastes). Interestingly, after decalcification the interior core of the cement paste with CNFs showed a more uniform areal porosity than that observed before decalcification. The initial greater local areal porosity associated with the presence of the CNF clusters disappeared during decalcification as a result of the dissolution of the $\mathrm{CH}$ plates and subsequent formation of $\mathrm{C}-\mathrm{S}-\mathrm{H}$, infiltrating the inter-fiber pore network of the CNF clusters. The dissolution-filling mechanism observed in the paste with CNFs had a more pronounced influence on the areal porosity after 125 days of decalcification by $\mathrm{NH}_{4} \mathrm{NO}_{3}$. Three zones of areal porosity were then identified for each cement paste: a low porosity, interior core; a clearly defined ring (middle layer) of higher porosity surrounding the core; and the outer layer, which was a combination of high and low porosity areas (Fig. 10). Overall, the different zones seen in the cement paste with CNFs exhibited lower areal porosities than that of the reference cement paste (outer layer: 5.3\% vs. $5.8 \%$; middle layer: $6.4 \%$ vs. $6.2 \%$; interior core: $4.2 \%$ vs. $4.6 \%$, respectively), indicating an influence of the dissolution-filling mechanism occurring within the CNF clusters as decalcification progressed. 


\subsection{Influence of CNF clustering and interphase region on the flexural response of decalcified cement pastes}

For both cement pastes, decalcification resulted in a steady decrease in flexural strength as exposure duration increased. The flexural strength of the decalcified cement pastes represented an overall flexural strength due to the cross-sectional heterogeneity induced by chemical degradation [30]. After 7 days of decalcification by $\mathrm{NH}_{4} \mathrm{NO}_{3}$, the cement paste with CNFs experienced a greater reduction in flexural strength compared to the reference paste ( $c a .37 \%$ flexural strength loss vs. ca. 28\%, respectively) (Fig. 11). The initial dissolution of the $\mathrm{CH}$ plates within the clusters and the leaching of calcium from the clusters to the surrounding cement paste combined with the associated porosity changes initially created weaker zones in the cement paste. As decalcification progressed, the loss of strength from the cement paste with CNFs slowed down. Both cement pastes then experienced similar additional decreases in strength from 7 to 28 days of decalcification by $\mathrm{NH}_{4} \mathrm{NO}_{3}$ (ca. 9\%). After 125 days of decalcification by $\mathrm{NH}_{4} \mathrm{NO}_{3}$, the cement paste with CNFs showed then a lesser strength reduction ( $c a .58 \%$ ) compared to the reference paste ( $c a .65 \%$ ), demonstrating the influence of the dissolution-filling mechanism occurring within the clusters on the mechanical properties of the paste. The dissolution-filling mechanism reduced the local porosity and improved the bond between the clusters and the surrounding cement paste.

Prior to decalcification, the cement paste with CNFs had a greater toughness than the reference paste ( 72,331 vs. $49,738 \mathrm{~J} / \mathrm{m}^{3}$, respectively), indicating a more pronounced ductility due to the presence of the CNF clusters (Fig. 12a). However, during decalcification, the flexural toughness of the paste with CNFs was influenced in a similar fashion to the strength. After 7 days of decalcification by $\mathrm{NH}_{4} \mathrm{NO}_{3}$, both cement pastes experienced a decrease in toughness. The rate of decrease for the cement paste with CNFs was, however, greater than that for the reference paste, indicating that the CNF clusters were acting as weak zones in the cement paste. After 125 days of decalcification by $\mathrm{NH}_{4} \mathrm{NO}_{3}$, the toughness of the cement paste with CNFs remained significantly greater than that of the reference paste, suggesting that the dissolution-filling mechanism occurring within the clusters during decalcification created a better bond with the 
surrounding cement paste. At all stages of decalcification by $\mathrm{NH}_{4} \mathrm{NO}_{3}$, the cement paste with CNFs maintained a statistically lower flexural modulus (95\% confidence, Welch's ttest) than the reference paste ( 2330 vs. $3535 \mathrm{MPa}$ before decalcification, 931 vs.

$1178 \mathrm{MPa}$ after 28 days of decalcification, and 787 vs. $1160 \mathrm{MPa}$ after 125 days, respectively) (Fig. 12b). The lower modulus seen in the cement paste with CNFs during decalcification by $\mathrm{NH}_{4} \mathrm{NO}_{3}$, coupled with the toughness behavior, indicated that the CNF clusters provided a more pronounced ductility to the material.

\subsection{Conclusions}

The chemo-mechanical behavior of cement pastes with and without CNFs exposed to a decalcifying environment was investigated. Results showed a strong coupling between decalcification, CNF clustering, microstructural evolution, and the flexural properties of the cement paste. The following conclusions could be drawn:

- Before decalcification, the $\mathrm{CNF}$ clusters showed a strong presence of $\mathrm{CH}$ plates intermixed with the CNFs and were surrounded by an interphase region of thickness independent of the cluster size.

- After 7 days of decalcification by $\mathrm{NH}_{4} \mathrm{NO}_{3}$, dissolution of the $\mathrm{CH}$ plates within the CNF clusters and leaching of calcium from the clusters to the surrounding cement paste caused increases in local porosity that initially created weaker zones and reduced the flexural strength retention of the cement paste.

- After 125 days of decalcification by $\mathrm{NH}_{4} \mathrm{NO}_{3}$, a dissolution-filling mechanism within the CNF clusters and chemical changes in the clusters' interphase regions reduced the local areal porosity of the cement paste and created a better bond with the surrounding cement paste, slowing down the loss of flexural strength compared to the reference cement paste.

- The CNF clusters provided, overall, a more pronounced ductility to the cement paste as decalcification progressed.

\section{Acknowledgements}


This research was supported by the National Science Foundation under NSF CAREER CMMI 0547024 and NSF GRFP DGE-0946822.

\section{References}

[1] Lawrence JG, Berhan LM, Nadarajah A. Elastic Properties and Morphology of Individual Carbon Nanofibers. ACS Nano. 2008;2(6):1230-6.

[2] Makar JM, Beaudoin, J.J. Carbon nanotubes and their applications in the construction industry. Proceedings of the first international symposium on nanotechnology in construction. Paisley, ScotlandJune 23-25, 2003. p. 331-41.

[3] Parveen S, Rana S, Fangueiro R. A Review on Nanomaterial Dispersion, Microstructure, and Mechanical Properties of Carbon Nanotube and Nanofiber Reinforced Cementitious Composites. Journal of Nanomaterials. 2013;2013:19. [4] Smilauer V, Hlavacek P, Padevet P. Micromechanical Anlaysis of Cement Paste with Carbon Nanotubes. Acta Polytechnica. 2012;52(6):22-8.

[5] Gay C, Sanchez F. Performance of Carbon Nanofiber-Cement Composites with a High-Range Water Reducer. Transportation Research Record: Journal of the Transportation Research Board. 2010;2142:109-13.

[6] Konsta-Gdoutos MS, Metaxa ZS, Shah SP. Highly dispersed carbon nanotube reinforced cement based materials. Cement and Concrete Research. 2010;40(7):1052-9. [7] Tyson B, Abu Al-Rub R, Yazdanbakhsh A, Grasley Z. Carbon Nanotubes and Carbon Nanofibers for Enhancing the Mechanical Properties of Nanocomposite Cementitious Materials. Journal of Materials in Civil Engineering. 2011;23(7):1028-35.

[8] Mendoza O, Sierra G, Tobón JI. Effect of the reagglomeration process of multiwalled carbon nanotubes dispersions on the early activity of nanosilica in cement composites. Construction and Building Materials. 2014;54(0):550-7.

[9] Mendoza O, Sierra G, Tobón JI. Influence of super plasticizer and $\mathrm{Ca}(\mathrm{OH}) 2$ on the stability of functionalized multi-walled carbon nanotubes dispersions for cement composites applications. Construction and Building Materials. 2013;47(0):771-8. [10] Yazdanbakhsh A, Grasley Z, Tyson B, Abu Al-Rub R. Distribution of Carbon Nanofibers and Nanotubes in Cementitious Composites. Transportation Research Record: Journal of the Transportation Research Board. 2010;2142:89-95. 
[11] Yazdanbakhsh A, Grasley Z. The theoretical maximum achievable dispersion of nanoinclusions in cement paste. Cement and Concrete Research. 2012;42(6):798-804. [12] Sanchez F, Ince C. Microstructure and macroscopic properties of hybrid carbon nanofiber/silica fume cement composites. Composites Science and Technology. 2009;69(7-8):1310-8.

[13] Siegfried M, Tola C, Claes M, Lomov SV, Verpoest I, Gorbatikh L. Impact and residual after impact properties of carbon fiber/epoxy composites modified with carbon nanotubes. Composite Structures. 2014;111(0):488-96.

[14] Gao L, Chou T-W, Thostenson ET, Godara A, Zhang Z, Mezzo L. Highly conductive polymer composites based on controlled agglomeration of carbon nanotubes. Carbon. 2010;48(9):2649-51.

[15] Gao L, Chou T-W, Thostenson ET, Zhang Z. A comparative study of damage sensing in fiber composites using uniformly and non-uniformly dispersed carbon nanotubes. Carbon. 2010;48(13):3788-94.

[16] Gao L, Chou T-W, Thostenson ET, Zhang Z, Coulaud M. In situ sensing of impact damage in epoxy/glass fiber composites using percolating carbon nanotube networks. Carbon. 2011;49(10):3382-5.

[17] Thomas JJ, Chen JJ, Allen AJ, Jennings HM. Effects of decalcification on the microstructure and surface area of cement and tricalcium silicate pastes. Cement and Concrete Research. 2004;34(12):2297.

[18] Chen JJ, Thomas JJ, Jennings HM. Decalcification shrinkage of cement paste. Cement and Concrete Research. 2006;36(5):801.

[19] Li GY, Wang PM, Zhao X. Mechanical behavior and microstructure of cement composites incorporating surface-treated multi-walled carbon nanotubes. Carbon. 2005;43(6):1239-45.

[20] Nochaiya T, Chaipanich A. Behavior of multi-walled carbon nanotubes on the porosity and microstructure of cement-based materials. Applied Surface Science. 2011;257(6):1941-5.

[21] Collins F, Lambert J, Duan WH. The influences of admixtures on the dispersion, workability, and strength of carbon nanotube-OPC paste mixtures. Cement and Concrete Composites. 2012;34(2):201-7. 
[22] Carde C, Escadeillas G, Francois R. Use of ammonium nitrate solution to simulate and accelerate the leaching of cement pastes due to deionized water. Magazine of Concrete Research. 1997;49(181):295-301.

[23] Burlion N, Bernard D, Chen D. X-ray microtomography: Application to microstructure analysis of a cementitious material during leaching process. Cement and Concrete Research. 2006;36(2):346-57.

[24] Scrivener KL, Patel HH, Pratt PL, Parrott LJ. Analysis of Phases in Cement Paste using Backscattered Electron Images, Methanol Adsorption and Thermogravimetric Analysis. MRS Online Proceedings Library. 1986;85.

[25] Le Chatelier H. Recherches expérimentales sur la constitution des mortiers hydrauliques. Annales des Mines 1887;2:345-420.

[26] CRC Handbook of Chemistry and Physics. 92nd ed. Boca Raton, FL.: CRC Press; 2011-2012.

[27] Cummins KM, Hammond DE. Molecular Diffusivities of Silicic and Gernamic Acids in Aqueous Solutions. American Geophysical Union Fall Meeting 2001. [28] Scrivener K, Crumbie A, Laugesen P. The Interfacial Transition Zone (ITZ) Between Cement Paste and Aggregate in Concrete. Interface Science. 2004;12(4):411-21. [29] Bentz DP, Garboczi EJ, Stutzman PE. Computer Modeling of the Interfacial Zone in Concrete. In: Maso JC, editor. Interfaces in Cementitious Composites: CRC Press; 1992. p. 107-16.

[30] Nguyen VH, Colina H, Torrenti JM, Boulay C, Nedjar B. Chemo-mechanical coupling behaviour of leached concrete: Part I: Experimental results. Nuclear Engineering and Design. 2007;237(20-21):2083-9.

\section{Figure Captions}

Fig. 1. 3D structure of the cement paste with CNFs showing the variability in size and shape of the CNF clusters throughout the paste. 
Fig. 2. (a) 2D size and (b) 2D spatial distributions of CNF clusters in a representative cement paste cross-section.

Fig. 3. SEM image and EDS spectra of (a) the interior of a representative CNF cluster prior to decalcification and (b) a representative CNF cluster after 125 days of decalcification by $\mathrm{NH}_{4} \mathrm{NO}_{3}$.

Fig 4. SEM image of the interphase region between a representative CNF cluster and the cement paste.

Fig. 5. EDS maps of a representative CNF cluster and interphase region before decalcification by $\mathrm{NH}_{4} \mathrm{NO}_{3}$.

Fig. 6. Cross-sections of the reference cement paste and paste with CNFs as a function of exposure duration to $\mathrm{NH}_{4} \mathrm{NO}_{3}$, showing the presence of visible degradation zones.

Fig. 7. (a) Calcium and (b) silicon profiles as a function of depth after 125 days of decalcification by $\mathrm{NH}_{4} \mathrm{NO}_{3}$.

Fig. 8. EDS maps of representative CNF clusters and interphase regions as a function of zone location after 7 days of decalcification by $\mathrm{NH}_{4} \mathrm{NO}_{3}$.

Fig. 9. EDS maps of representative CNF clusters and interphase regions as a function of zone location after 125 days of decalcification by $\mathrm{NH}_{4} \mathrm{NO}_{3}$.

Fig. 10. 3D areal porosity contour plots for the (a) reference cement paste and (b) paste with $\mathrm{CNF}$ s before and after decalcification by $\mathrm{NH}_{4} \mathrm{NO}_{3}$.

Fig. 11. Flexural strength of cement pastes with and without CNFs as a function of exposure to $\mathrm{NH}_{4} \mathrm{NO}_{3}$.

Fig. 12. Flexural (a) toughness and (b) modulus of cement pastes with and without CNFs as a function of exposure to $\mathrm{NH}_{4} \mathrm{NO}_{3}$. 


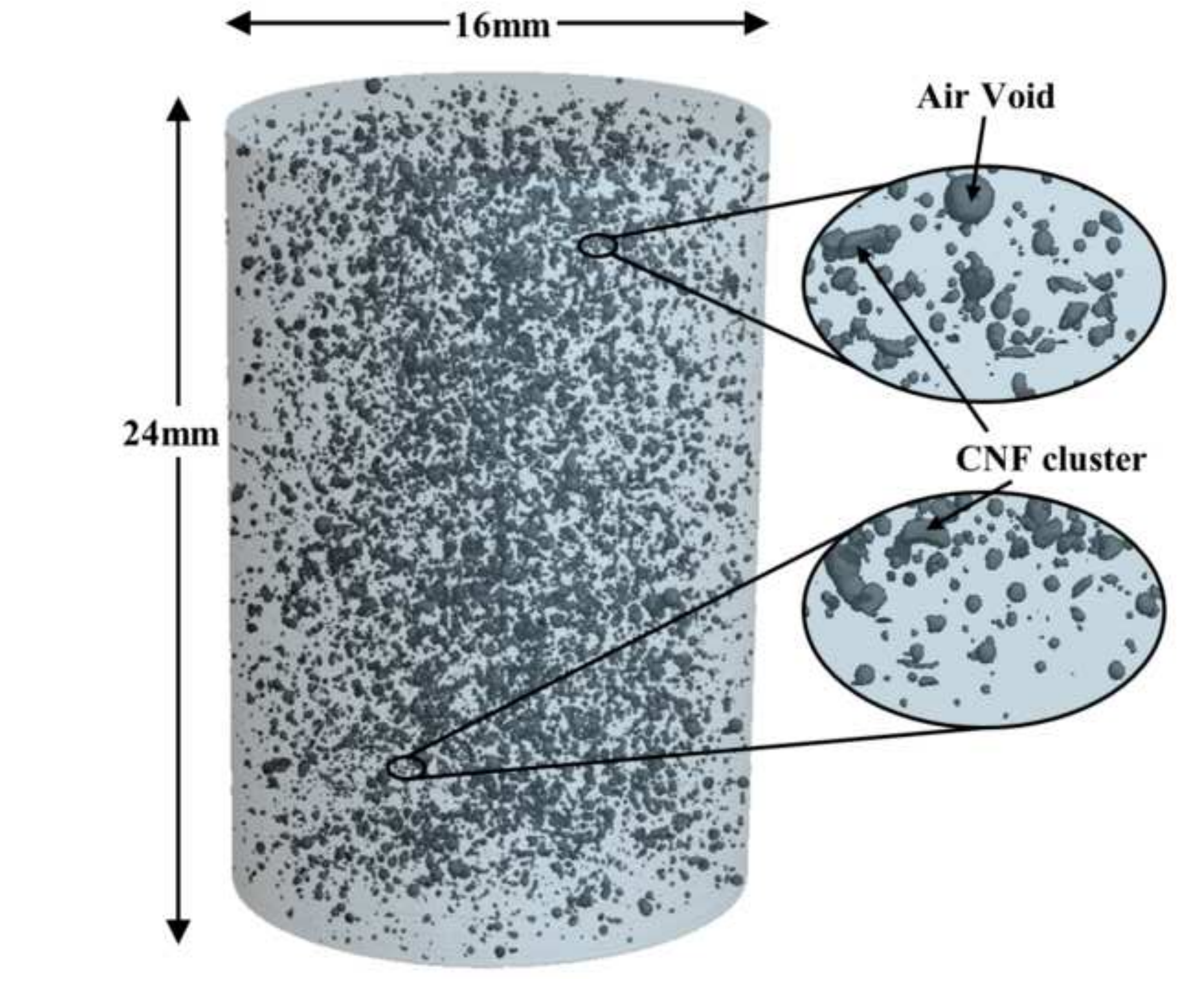

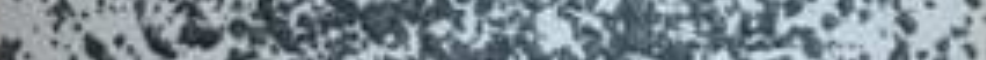

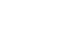

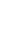


(a)
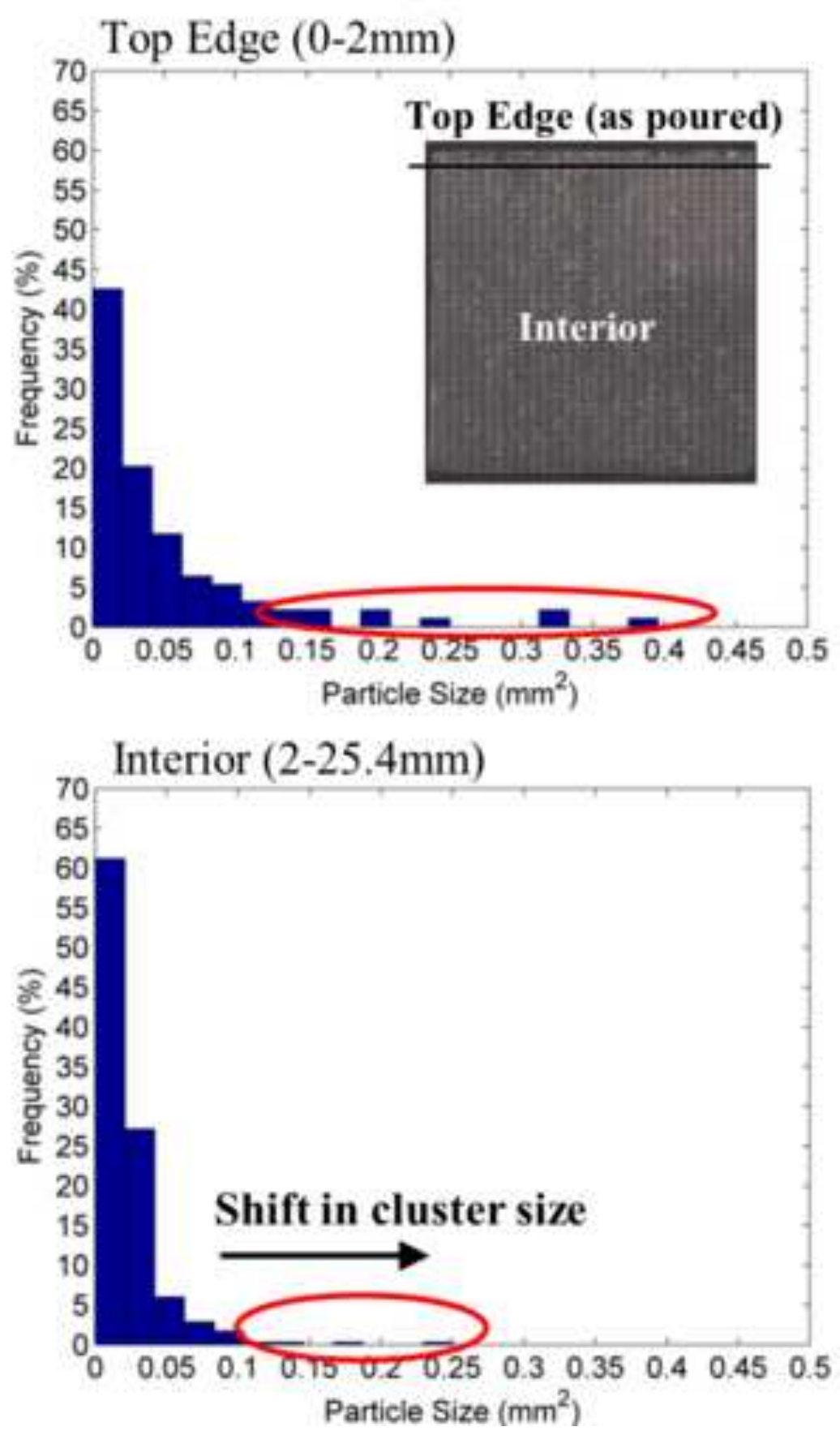

(b)
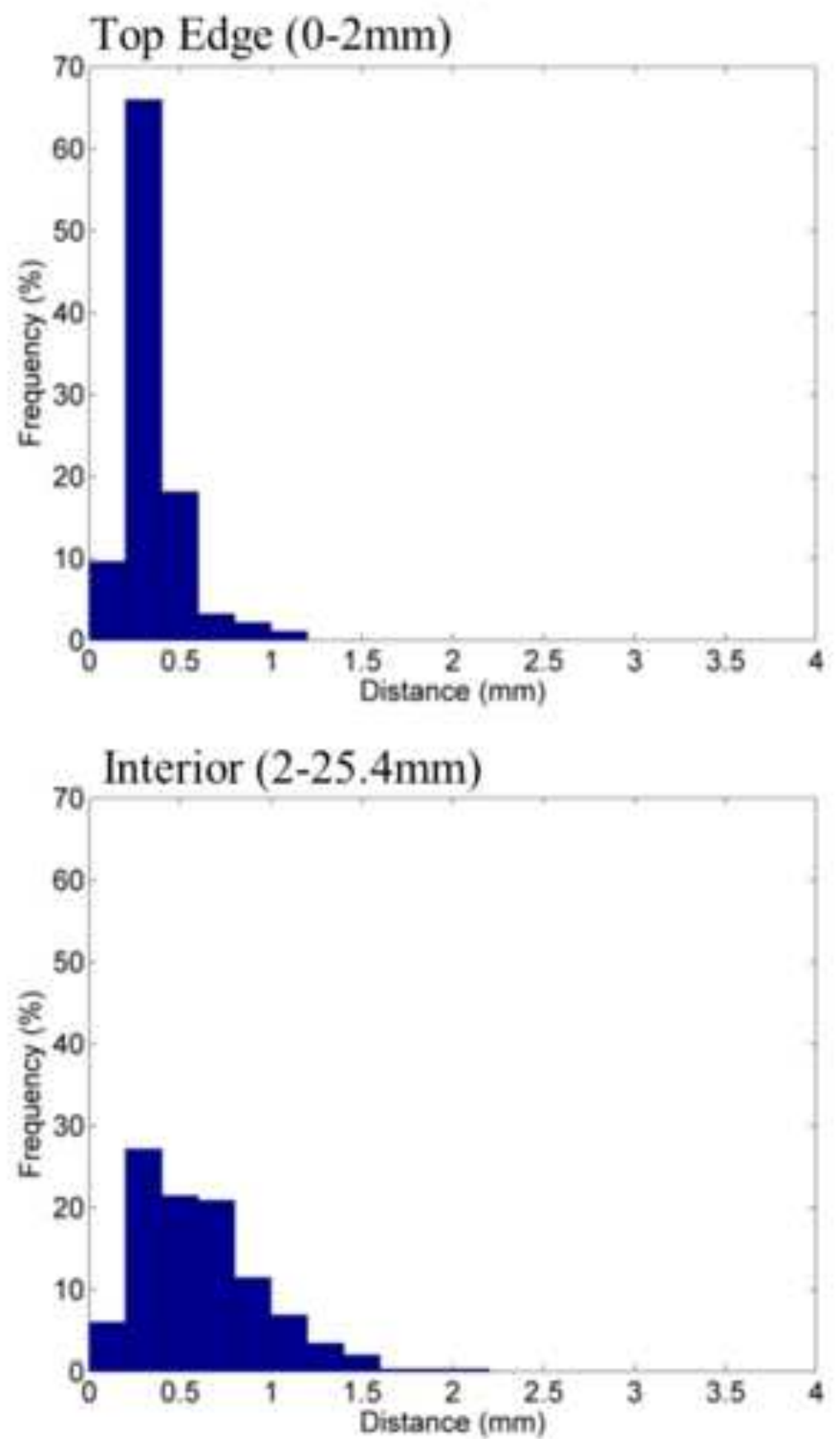
(a)

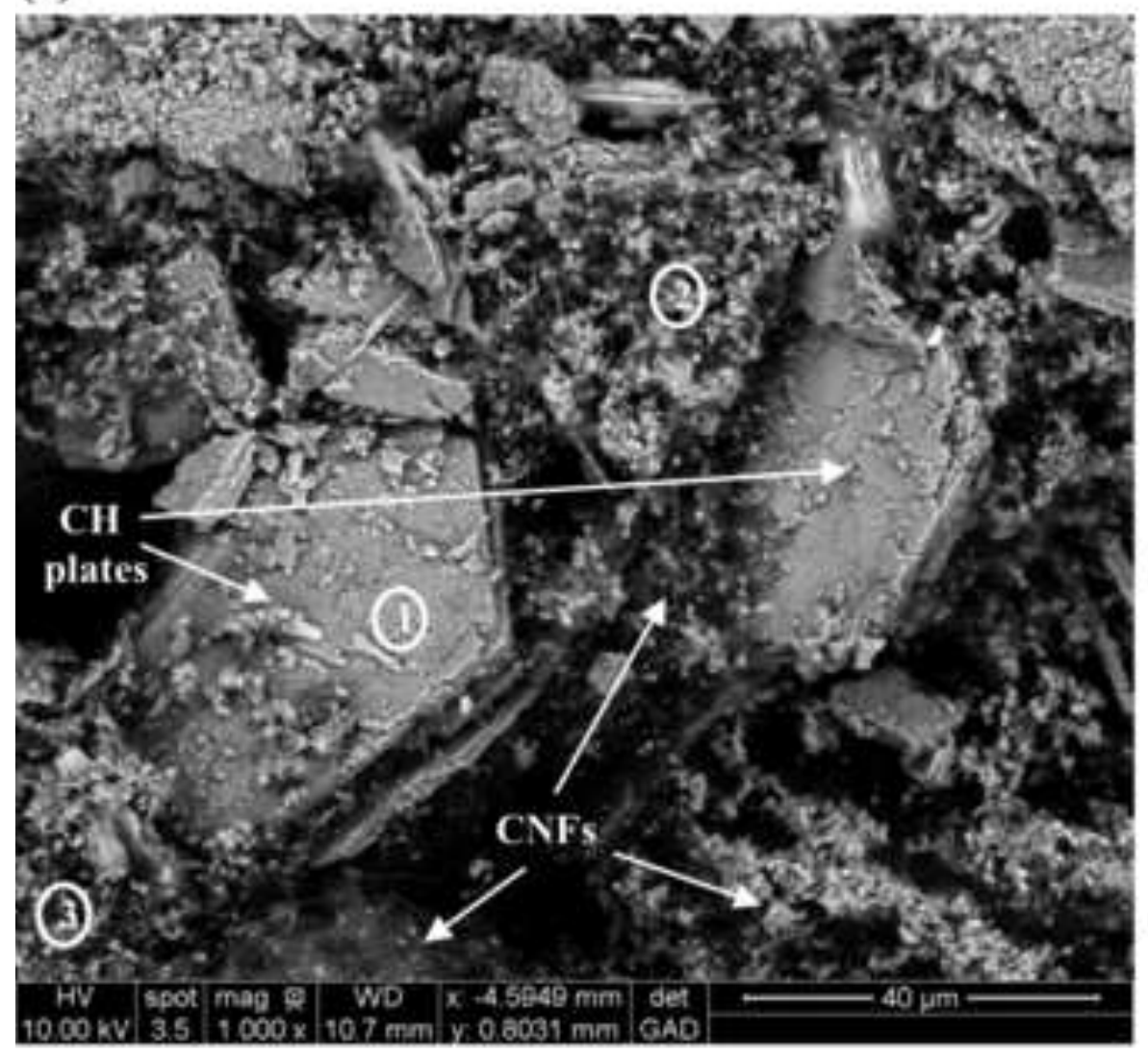

(b)

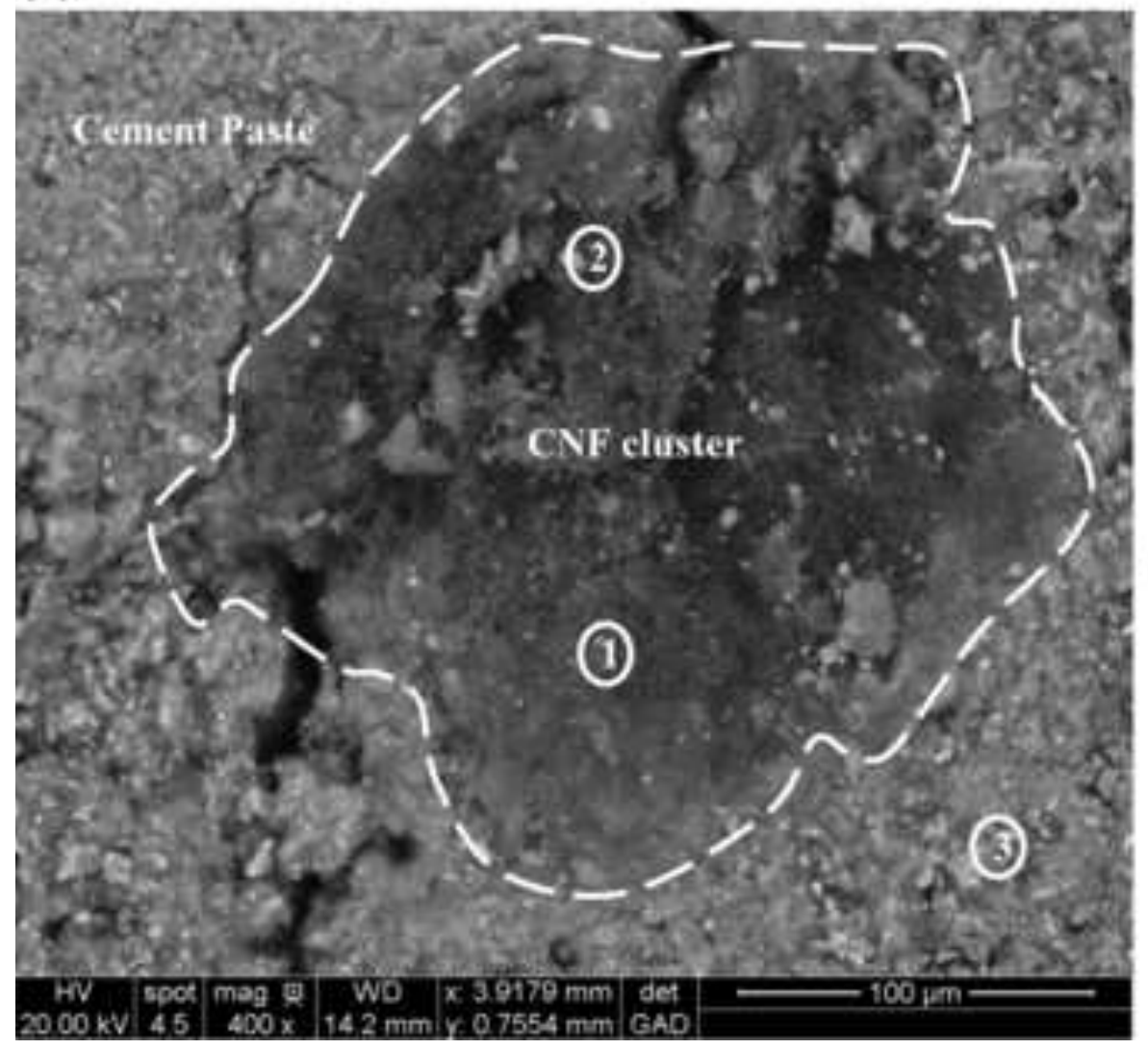

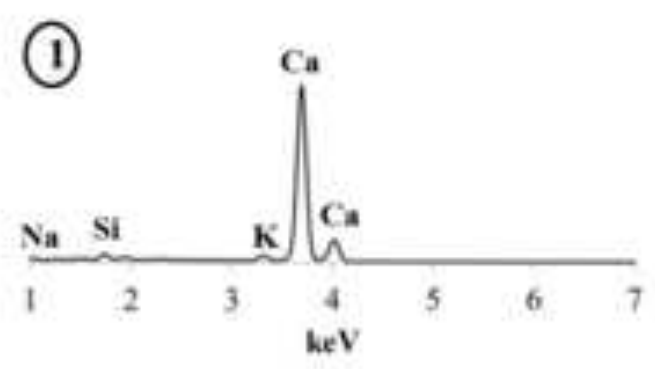

(2)

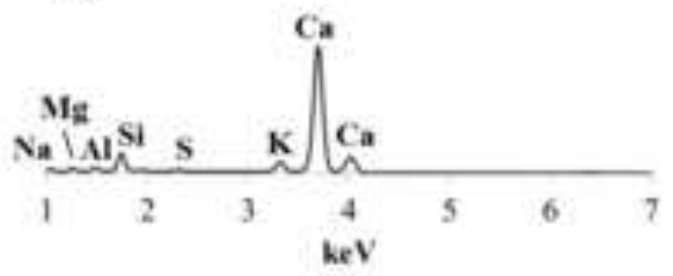

(3)

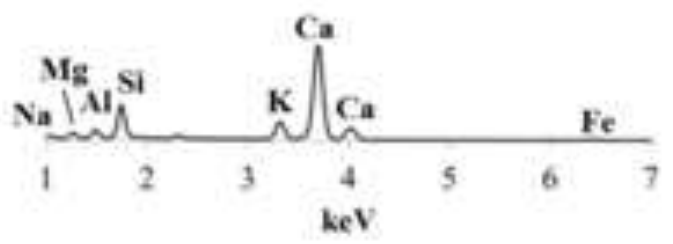

(1) $\quad$ Ca/Si Ratio $=\mathbf{1 . 0 4}$

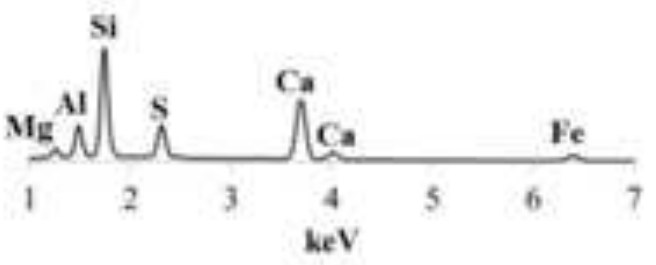

(2) $\mathrm{Ca} / \mathrm{Si}$ Ratio $=1.60$
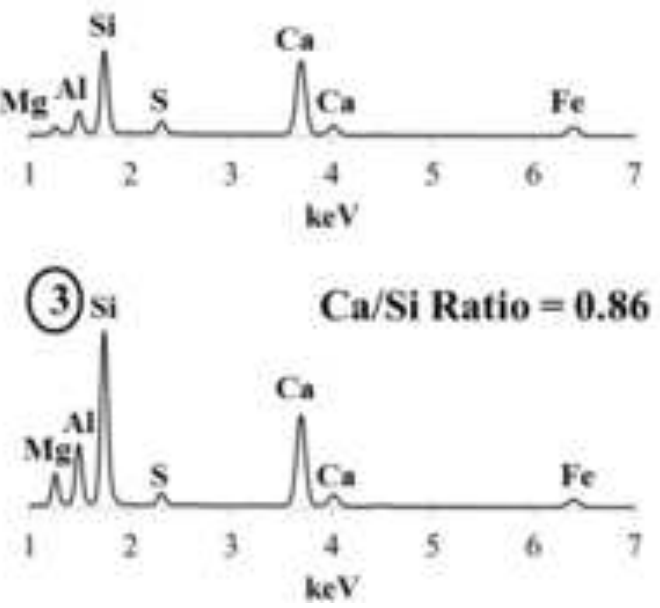


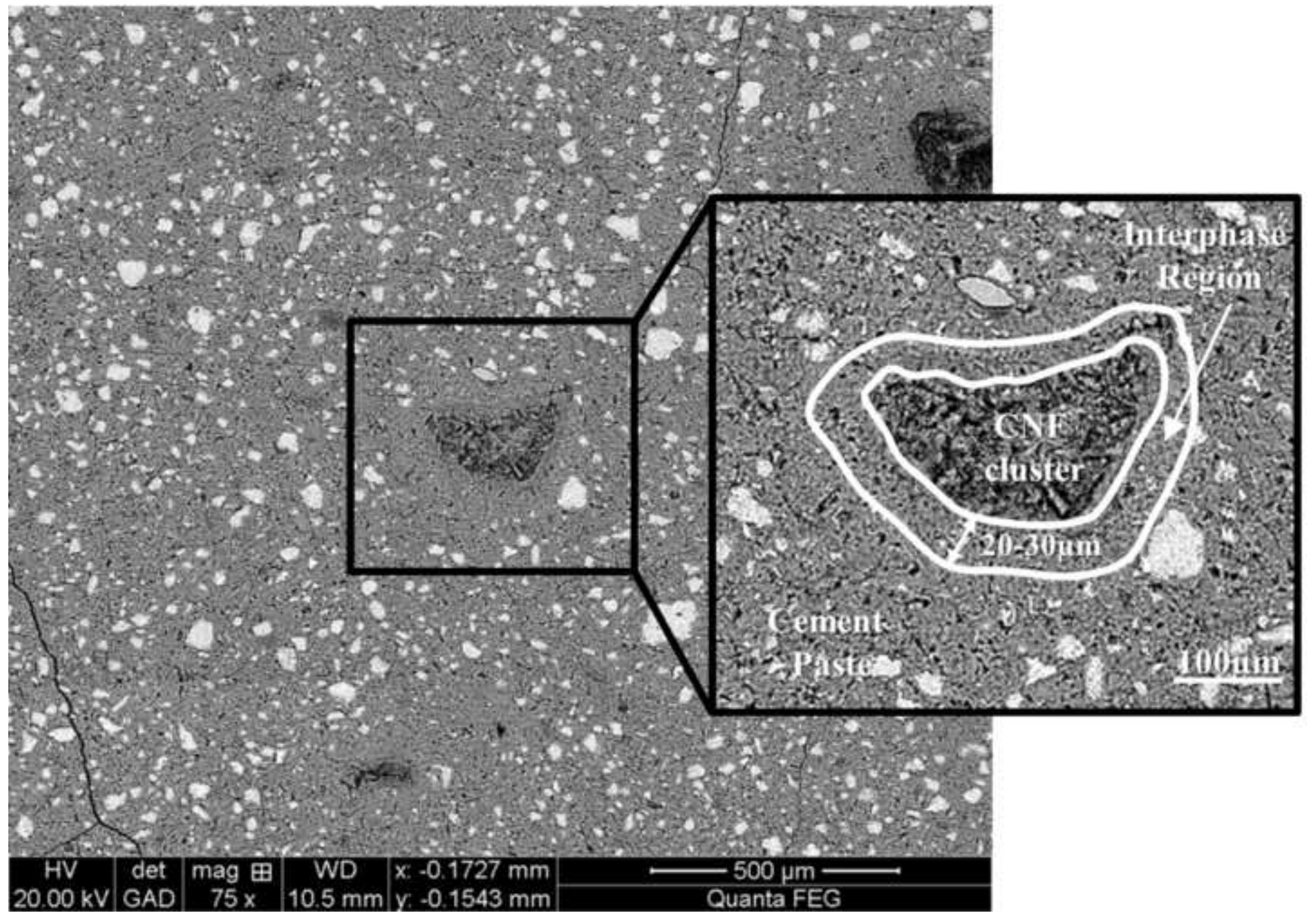




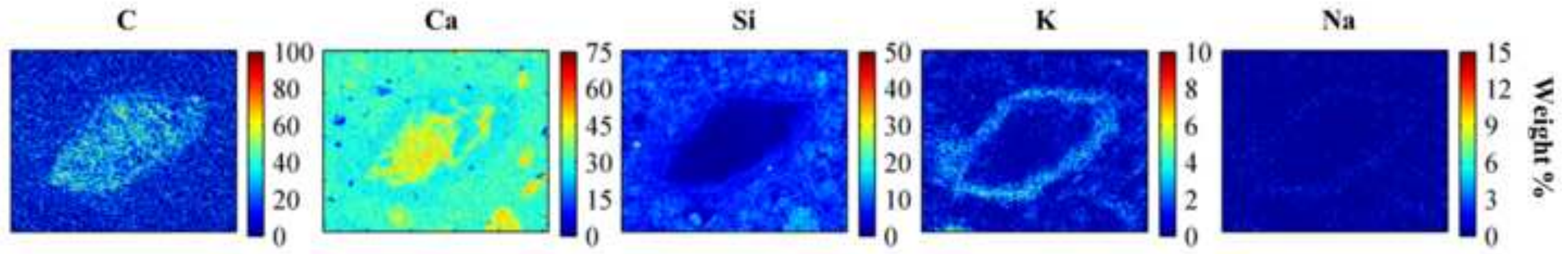




\section{Reference Paste Paste w/ CNFs}

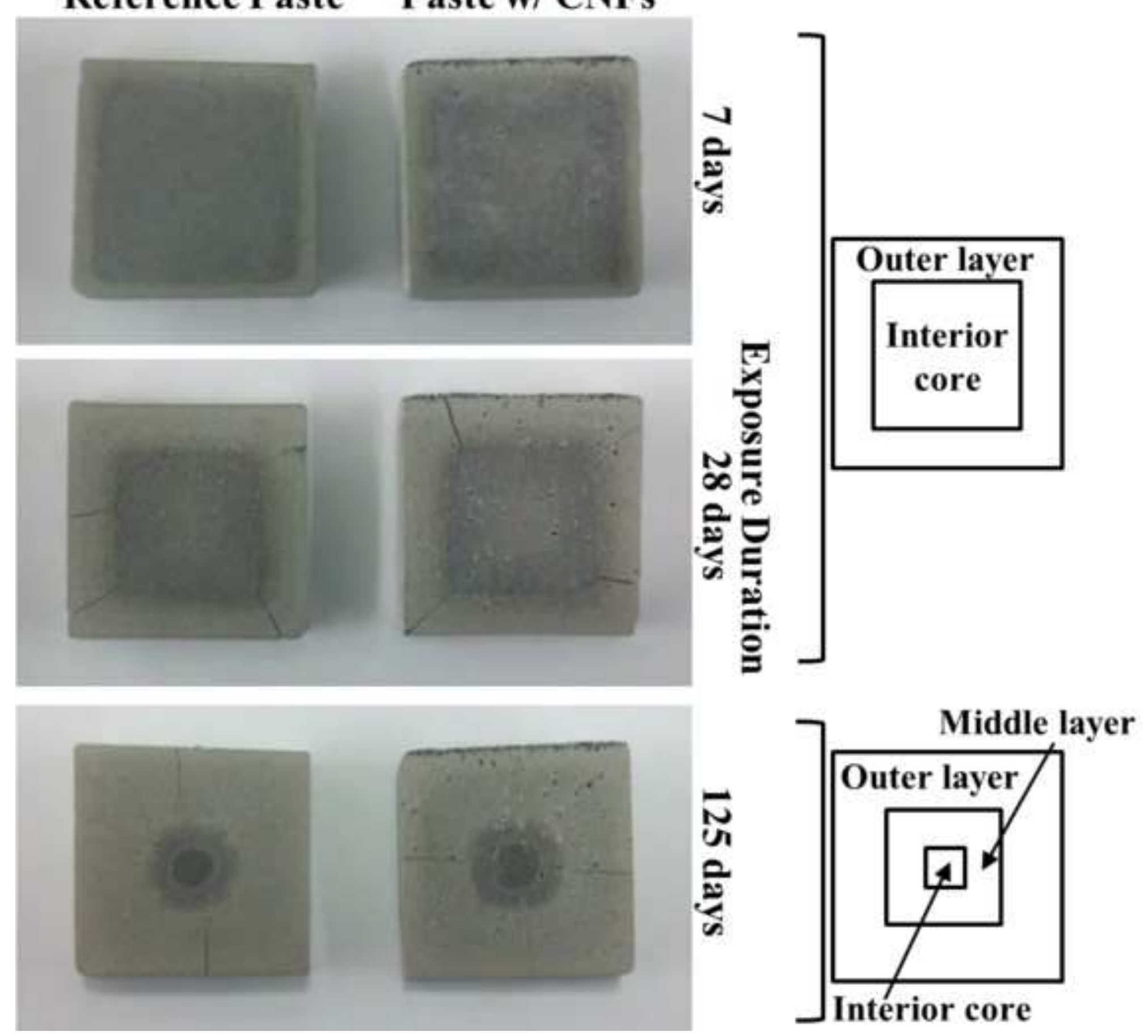


(a)

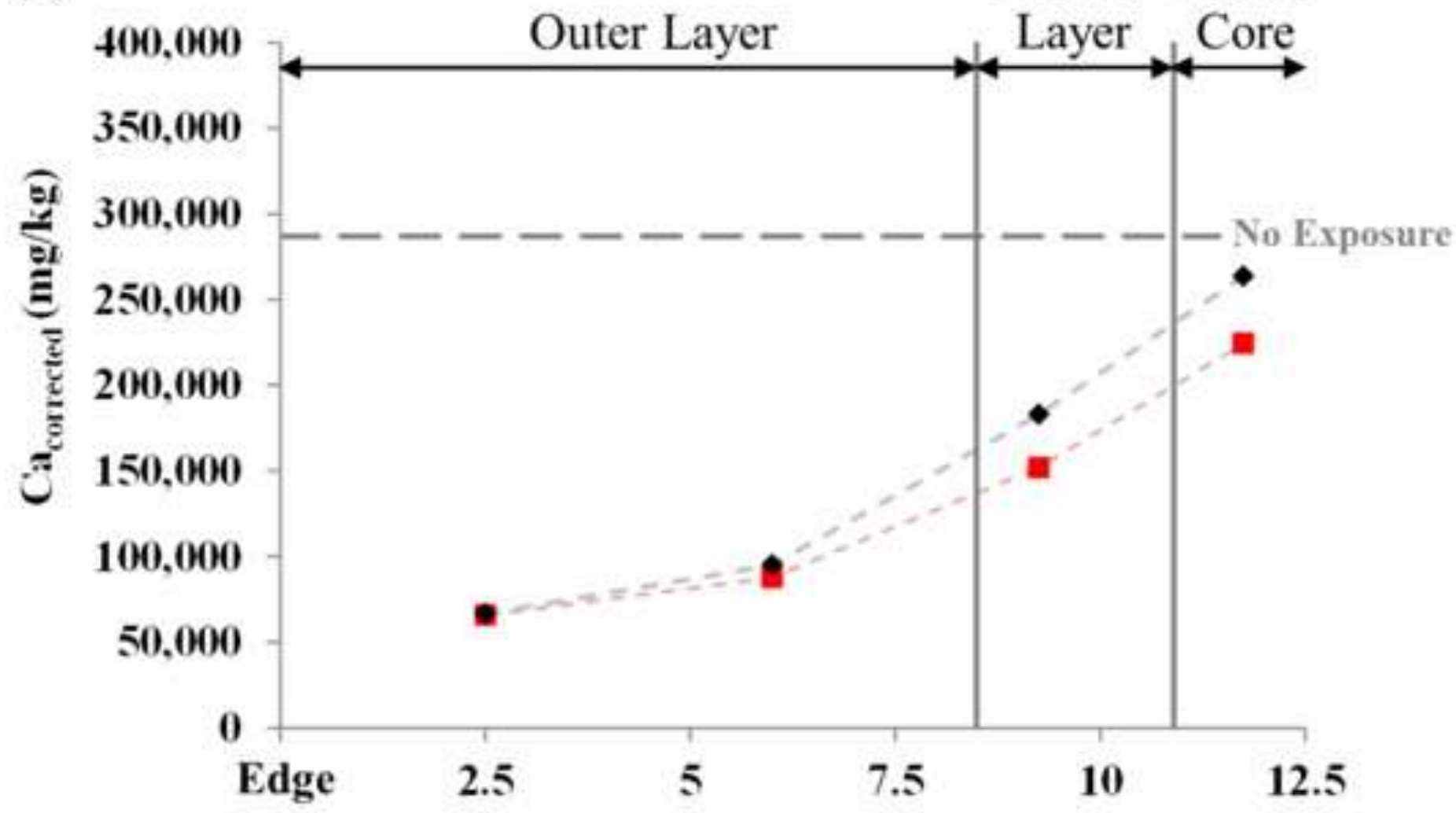

- - Reference paste

- Paste w/ CNFs

(b)

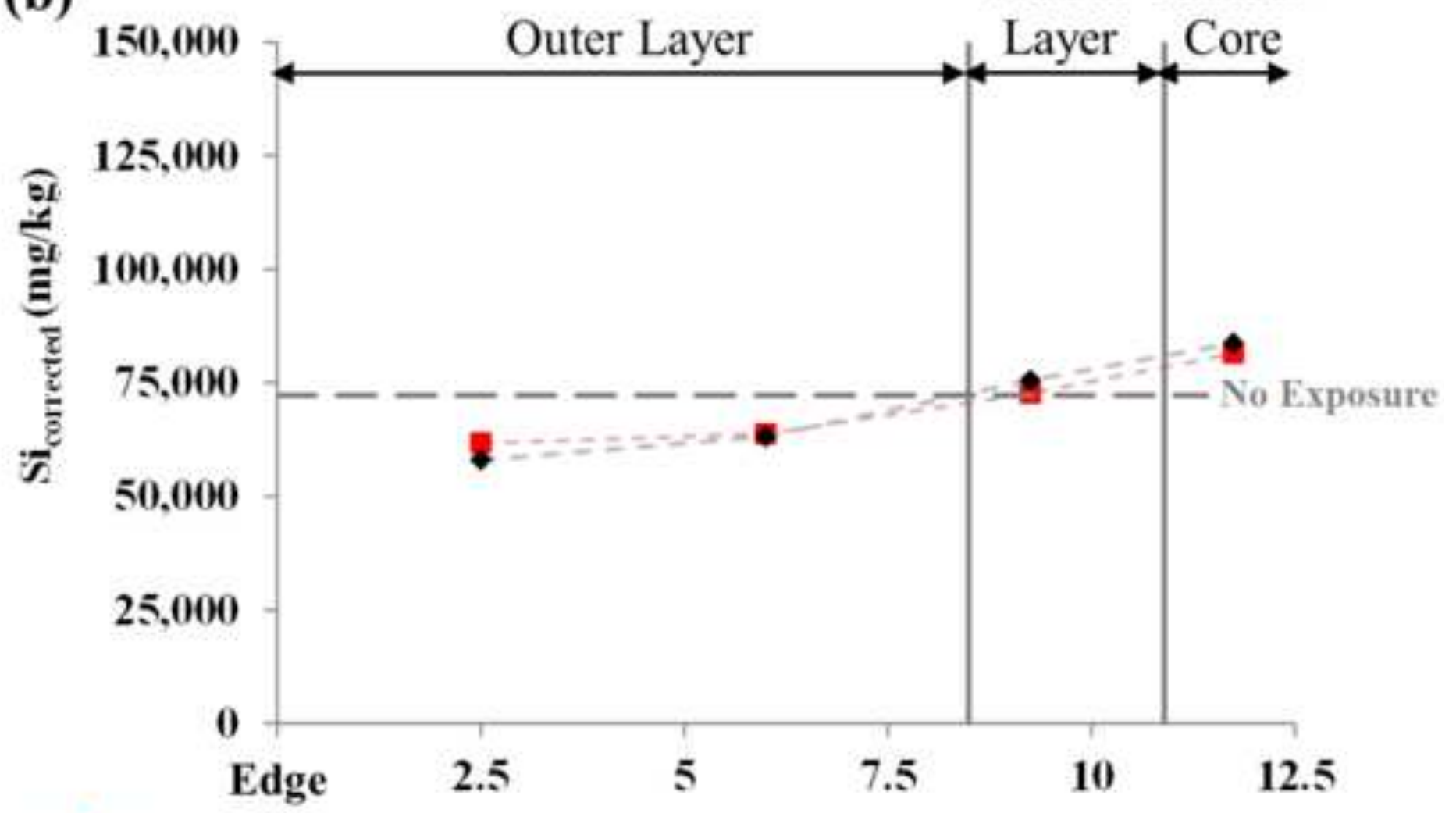

- E - Reference paste

Distance from edge ( $\mathrm{mm}$ )

- Paste w/CNFs

Middle Interior

Distance from edge (mm)

Middle Interior Layer Core 


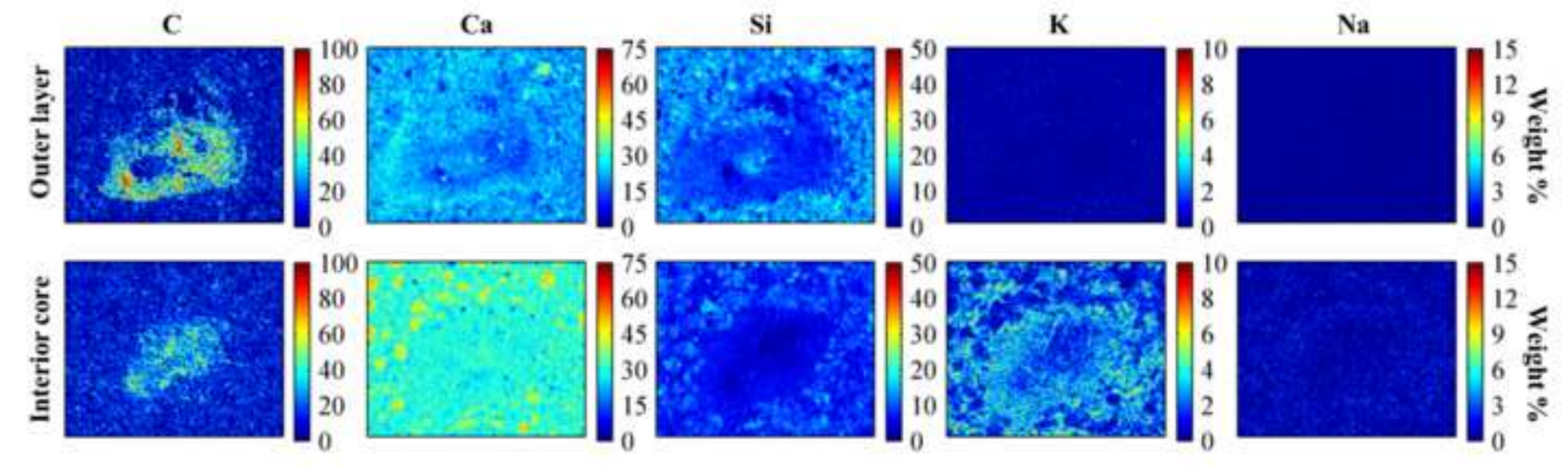




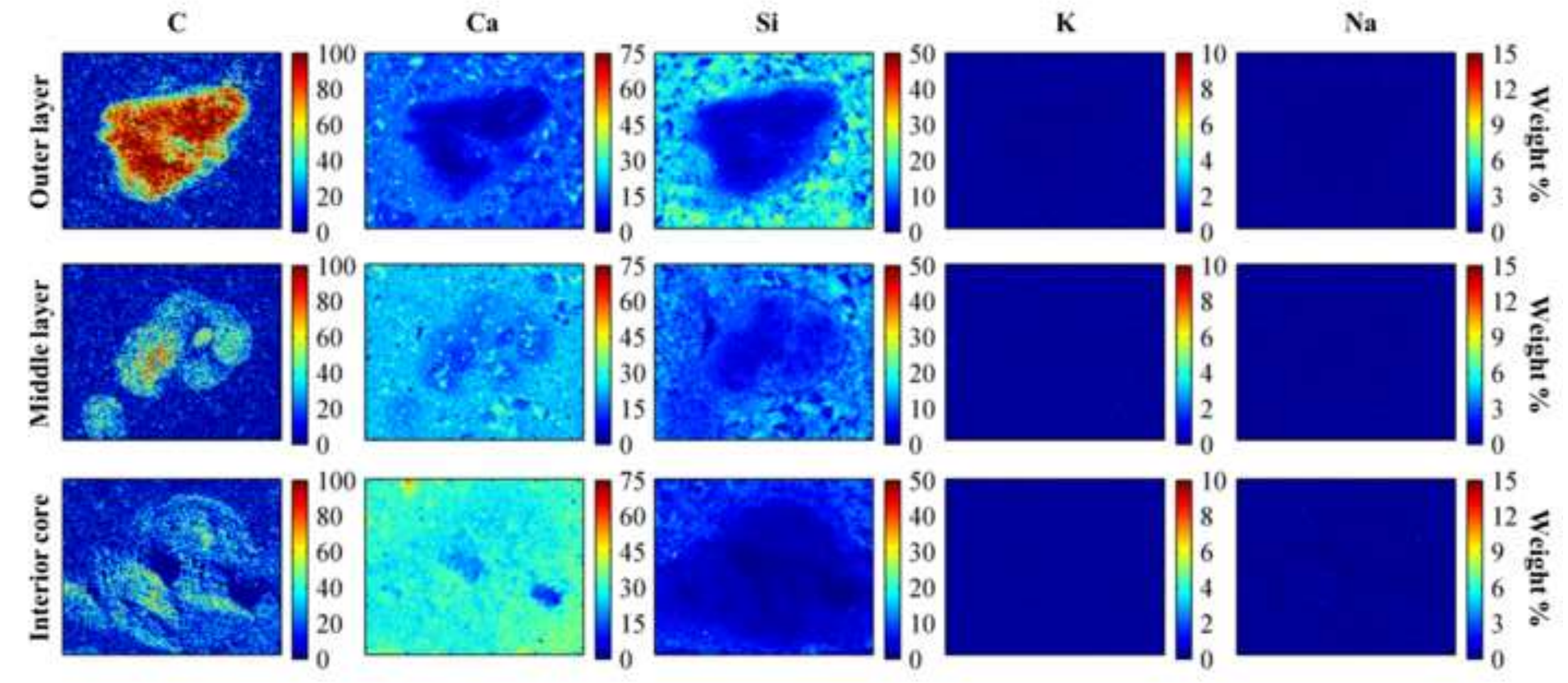


(a) Reference Paste

䓀
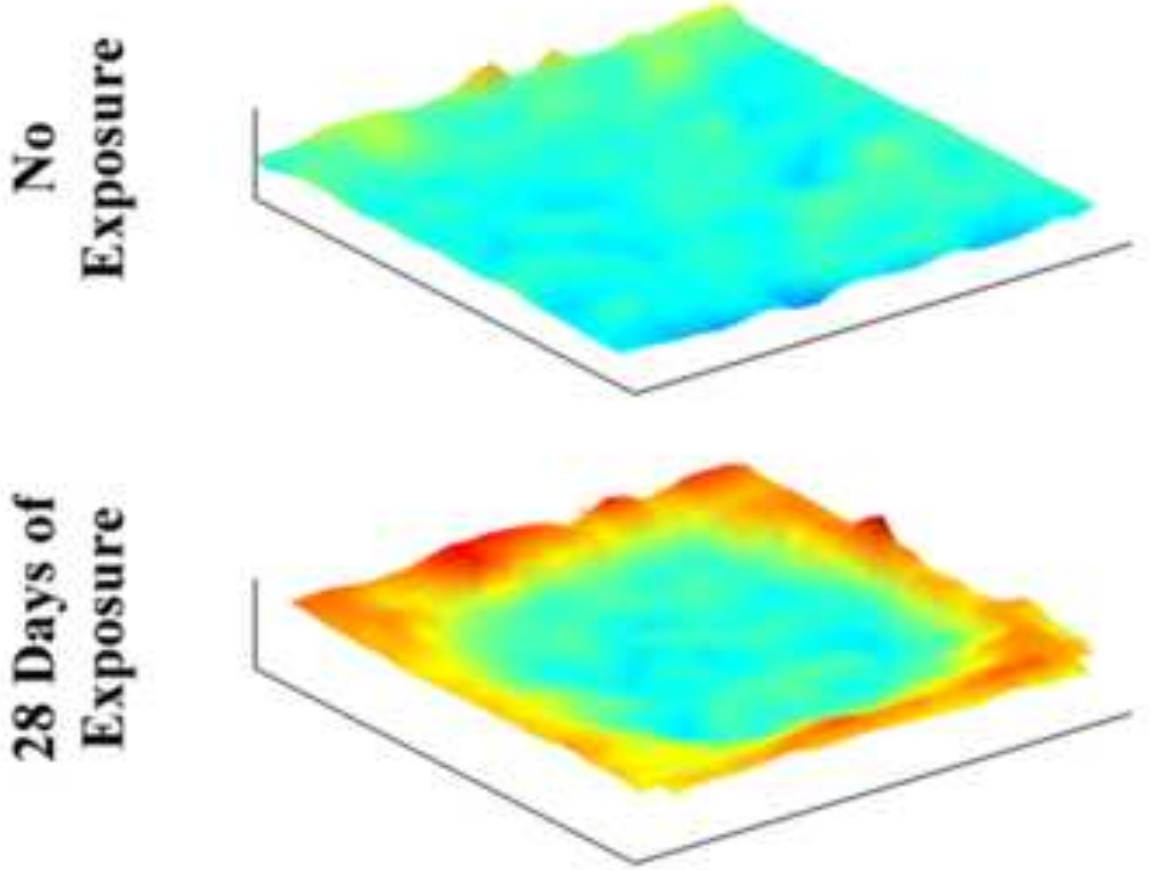

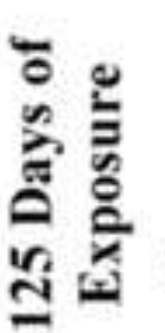

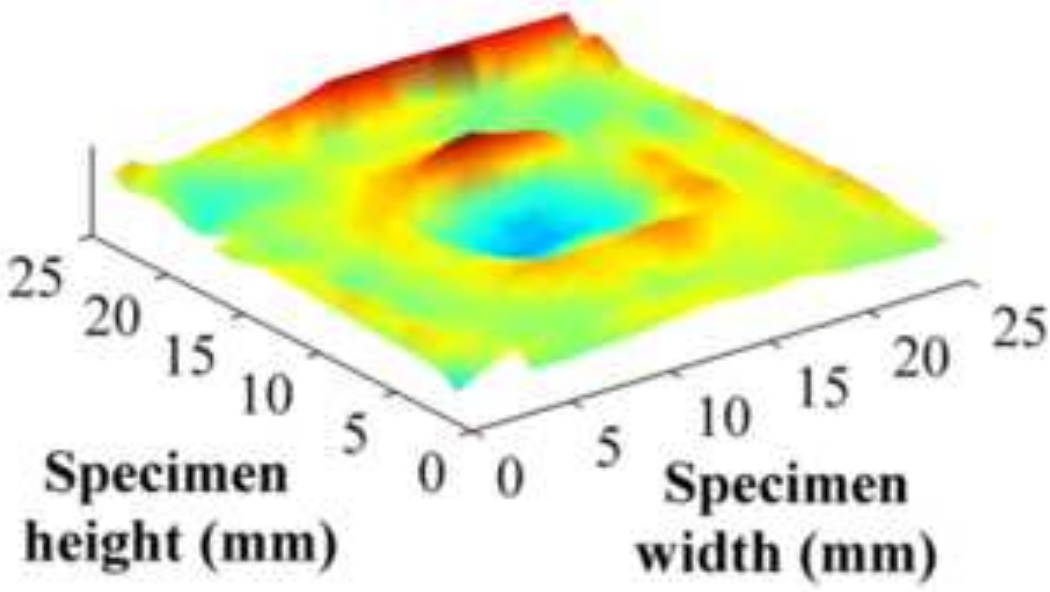

Specimen height (mm) (b) Paste w/ CNFs


10

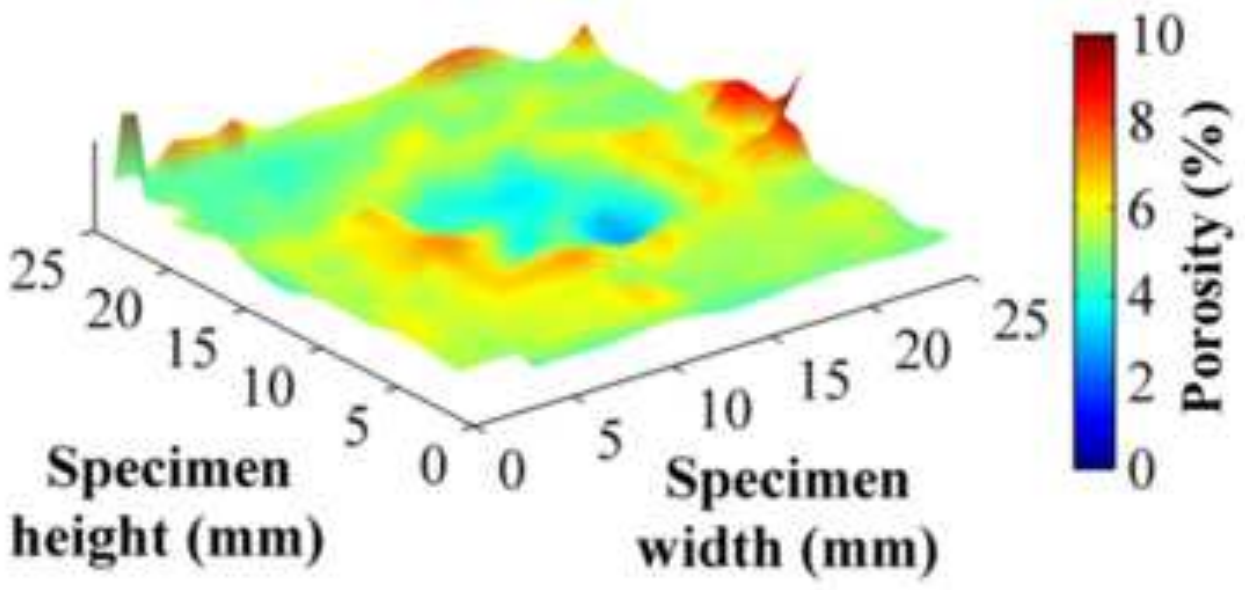




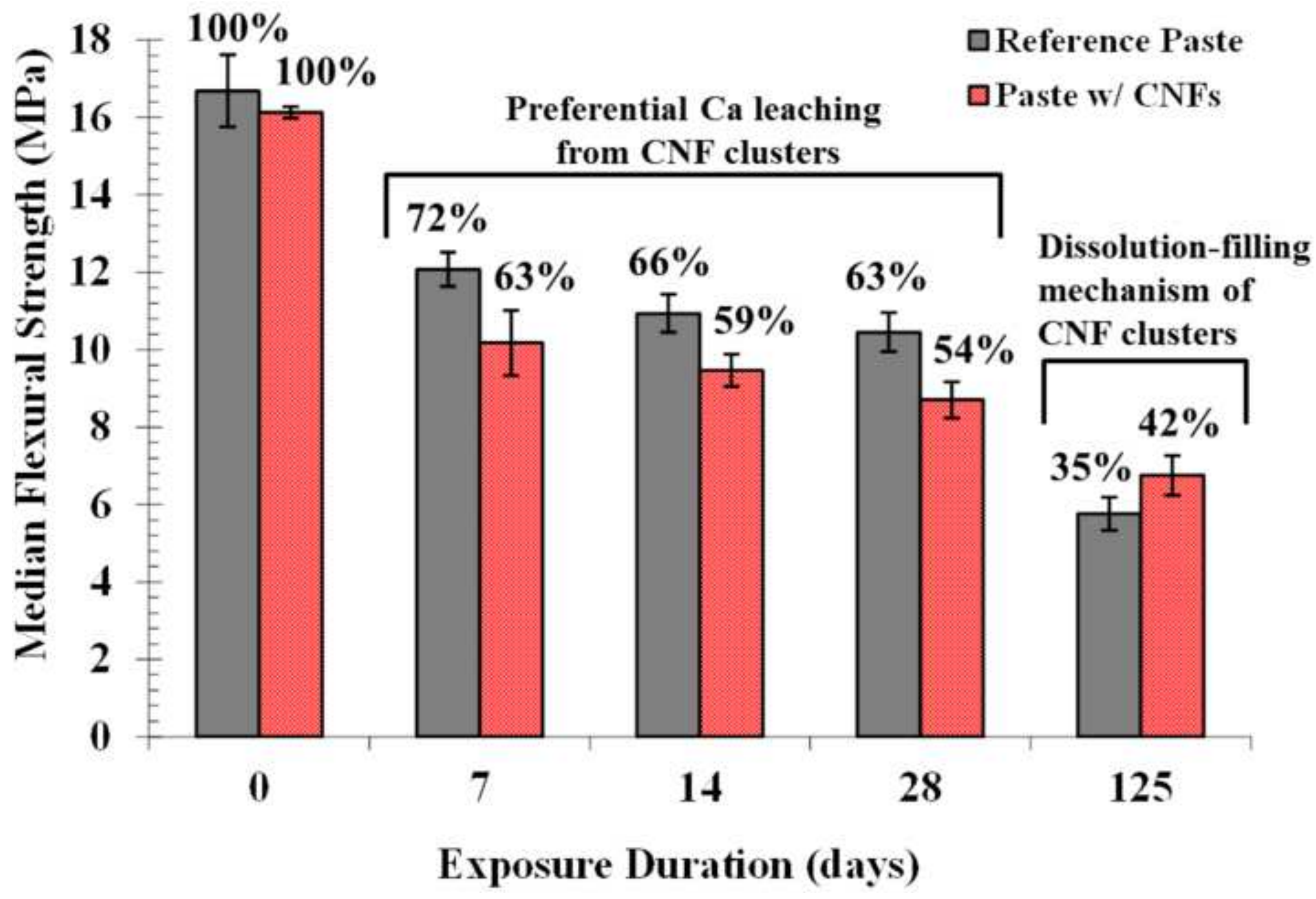



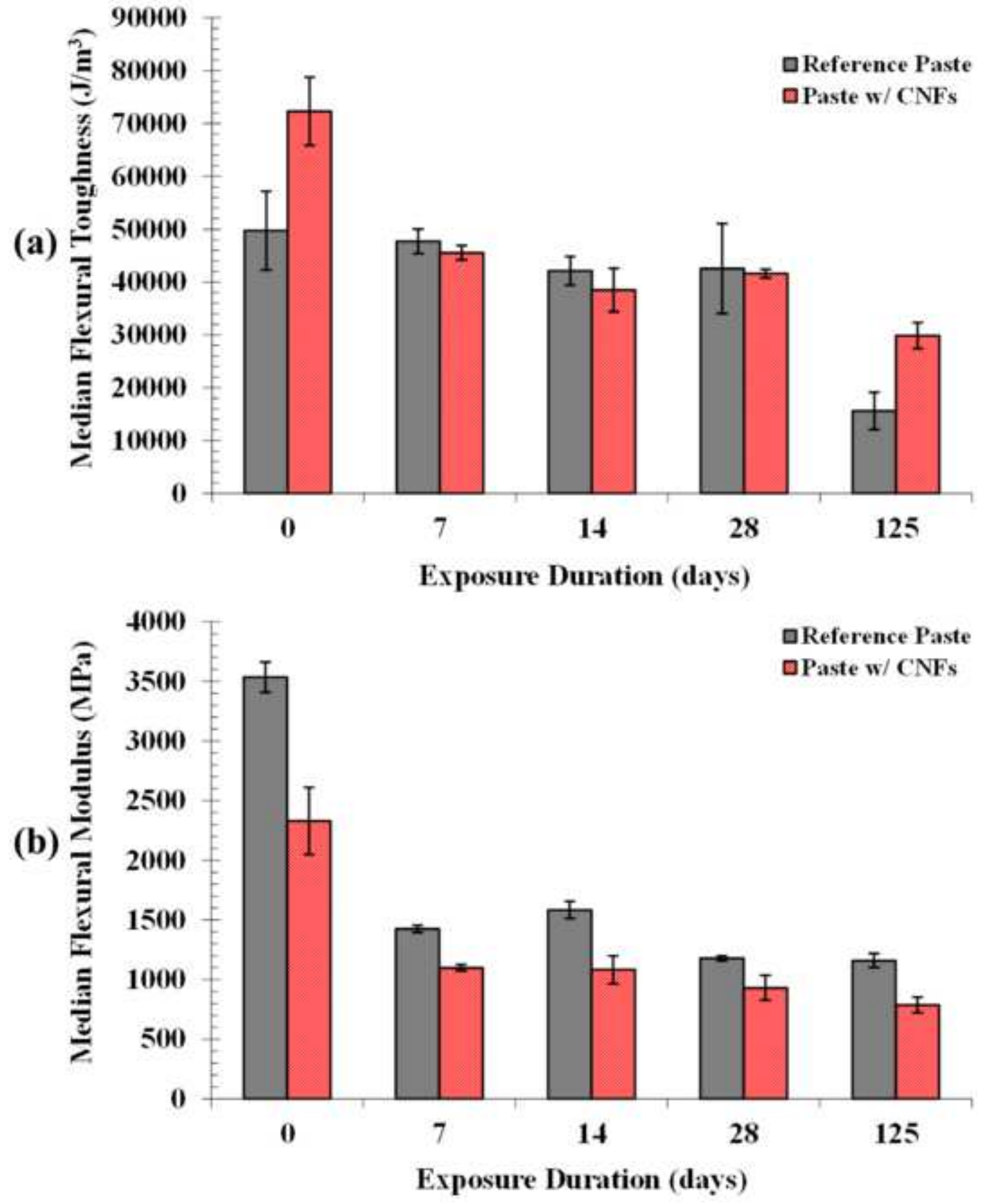